\title{
REALISMO JURÍDICO E POSITIVISMO JURÍDICO: Uma Conexão Necessária
}

\author{
http://dx.doi.org/10.21527/2176-6622.2019.52.184-194
}

Recebido em: 7/4/2019

Modificações requeridas em: 22/9/2019

Aceito em: 15/10/2019

\section{Mônica Emília Moreira}

Mestre em Direito pela Pontifícia Universidade Católica de Minas Gerais, com ênfase em Teoria do Direito. Advogada militante na área de Direito Civil. Bacharel em Direto pela Pontifícia Universidade Católica de Minas Gerais. http://lattes.cnpq.br/5929479410511436. monicasajpuc@gmail.com

\section{RESUMO}

O presente artigo traz a discussão acerca da conexão entre duas importantes teorias do Direito: o Positivismo Jurídico e o Realismo Jurídico. Iniciamos com a exposição das principais ideias do Realismo Jurídico norte-americano e escandinavo, sob a ótica de seus diversos autores. Dentro do Realismo presente nos Estados Unidos destacamos sua permeabilidade no sistema da Common Law, uma vez que o Direito norte-americano se alicerça neste. Ao abordarmos a teoria do Positivismo Jurídico, fez-se necessário um recorte teórico em seus pontos principais, para que fosse possibilitada sua análise em relação ao Realismo Jurídico. Assim, o positivismo aqui apresentado encontra-se sintético em relação a sua vastidão teórica. $\mathrm{E}$, por fim, apresentamos as conexões vislumbradas entre as duas teorias, alicerçadas na posição teórica dos variados autores que analisamos ao longo do texto. A metodologia adotada neste trabalho foi a revisão bibliográfica e documental, utilizando-se do método dedutivo para se alcançar os resultados apresentados.

Palavras-chave: Realismo jurídico. Positivismo jurídico. Common Law.

\section{LEGAL REALISM AND LEGAL POSITIVISM: A NECESSARY CONNECTION}

\section{ABSTRACT}

This article discusses the connection between two important theories of law, Legal Positivism and Legal Realism. We begin by exposing the main ideas of North American and Scandinavian Legal Realism, from the perspective of its various authors. Within the Realism present in the United States we highlight its permeability in the Common Law system, since US law is based on it. When approaching the theory of Legal Positivism, it was necessary a theoretical cut in its main points, turning the Legal Realism relation analysis possible. Thus, the positivism presented here is synthetic in relation to its theoretical vastness. Finally, we present the glimpsed connections between two theories, based on the theoretical position of the various authors that we deal with throughout the text. The methodology adopted in this work was the bibliographic and documentary revision, using the deductive method to reach the presented results.

Keywords: Legal realism. Legal positivism. Common Law.

\section{SUMÁRIO}

1 Introdução. 2 O Realismo Jurídico Americano. 3 O Realismo Jurídico Escandinavo. 4 Considerações Acerca do Positivismo Jurídico. 5 Conectando o Positivismo Jurídico ao Realismo Jurídico. 6 Conclusão. 7 Referências. 


\section{INTRODUÇÃO}

O Realismo Jurídico desenvolveu-se na primeira metade do século 20 nos Estados Unidos e na Escandinávia, e em razão disso sua corrente divide-se em realismo americano e realismo escandinavo, os quais argumentam ser efetivo o Direito que decorre de fatos sociais ou históricos, e não o idealizado; desta forma não pode o Direito ter unicamente como requisito a validade, sendo necessário também o requisito da eficácia.

O Positivismo Jurídico surge em meados do século 19 como uma reação contrária à fundamentação do Direito em bases metafísicas. Assim, seus teóricos buscam fundar as questões jurídicas a partir de dados fornecidos pela experiência, ou seja, é por aqui que pode ser provado empiricamente e não por fatores externos ao mundo físico.

Diante desse cenário de duas teorias, em certa medida contemporâneas, qual seria a conexão, a influência entre as duas correntes de pensamento? Ao investigar a temática tomou-se como ponto de partida a exposição das correntes de pensamento estudadas, buscando encontrar os pontos de contato entre ambas que fosse capaz de estabelecer uma conexão entre elas.

Em um segundo momento rastreou-se os pontos convergentes entre as duas teses que seriam capazes de responder a nossa indagação. Haveria entre o Positivismo e o Realismo uma conexão teórica, ou seriam duas formas distintas de pensar o Direito?

O presente texto é fruto de uma pesquisa bibliográfica e documental, na qual foi empregado o método de análise hipotético-dedutivo dos escritos examinados. Assim sendo, apresenta-se aqui uma resposta provisória ao problema levantado, de que há sim conexão entre as teorias do Realismo e do Positivismo.

\section{O REALISMO JURÍDICO AMERICANO}

O pensamento jurídico norte-americano tem como ponto de partida a promulgação de sua Constituição em 1787, sendo edificada sobre o conceito de um Estado neutro, imparcial e não redistributivista, tudo isso ancorado no princípio da liberdade. Tal organização política recebeu a denominação de pensamento clássico por M. J. Horwitz. A ciência do Direito, nessa concepção clássica, estava embasada no estudo de casos, portanto o Direito estava contido em livros impressos e a Constituição, nessa época, deveria ser interpretada em consonância com a vontade dos Founding Fathers ${ }^{1}$ (AGUILAR, 1999).

Devido, no entanto, às constantes mudanças sociais provocadas pela revolução tecnológica e industrial, bem como a centralização do poder econômico e o desequilíbrio social promoveram uma necessidade de adaptação da Common Law à realidade americana, tendo por fim propiciar uma maior flexibilidade e adaptação das leis constitucionais (BOBBIO, 2006).

O realismo jurídico desponta neste cenário como um sopro de modernidade no Direito norte-americano, rejeitando assim o formalismo normativo. A partir deste momento não mais se faria alusão aos pais fundadores da Constituição para solucionar os conflitos. Seus teóricos defendem a caráter dinâmico do Direito, assim como sua criação judicial. Argumentam estar a sociedade em fluxo mais célere que o Direito, devendo este ser constantemente revisado. Segundo este pensamento, o Direito a ser seguido não é o que está contido em livros, Law in books, mas sim o Direito em ação, Law in action (JORGE, 2012).

Um dos primeiros teóricos a tratar sobre realismo nos Estados Unidos foi Karl Llewellyn. Sua abordagem a respeito do tema consistia em uma valoração da decisão judicial em detrimento do direito material (BODENHEIMER, 1966). Afirmava este autor: "O que fazem esses funcionários relativamente aos litígios vem a ser, para mim, o próprio direito" (p. 139).

Llewellyn defende que o foco do estudo do Direito deve ser os juízes. Nesse sentido, as sentenças devem ser estudadas com a finalidade de entender como decidem os tribunais. O estudo da sentença deve pautar-se por três aspectos: o que os tribunais têm decidido, identificando-se, assim, a regra utilizada; como e com que precisão os tribunais têm interpretado as normas e, por fim, e na opinião do teórico Karl Llewellyn, a mais difícil, se o que a Corte decidiu era desejável, ou seja, se a decisão foi ao encontro do que era esperado (JORGE, 2012).

\footnotetext{
${ }^{1}$ Pais fundadores.
} 
Jerome Frank, pertencente também ao movimento denominado Realismo Jurídico, defende que o juiz, ao decidir, parte de conviç̧ões pessoais, sentimentais, valendo-se até mesmo de intuições e pressentimentos. Sendo assim, a norma jurídica, para ele, não constitui a base das decisões judiciais (BODENHEIMER, 1966). Frank defende que a certeza, a qual por vezes é evocada como um pilar do ordenamento jurídico, não passa de uma ilusão infantil do princípio da autoridade, acreditando ser o Direito uma contínua criação, estando, portanto, em constante movimento (JORGE, 2012).

Frank possuía uma incredulidade em relação à segurança das decisões judiciais, pois, após ter ascendido à Corte Federal, deparou-se com várias situações, pelas quais pôde constatar inúmeras fontes de erro que podem atuar determinantemente na solução final do caso. Entre elas destacou a desatenção dos jurados, a ignorância dos juízes e advogados, assim como a volatilidade das testemunhas (BODENHEIMER, 1966).

Bodenheimer (1966), em sua obra, ao tratar do Realismo Jurídico, adverte que ele não chega a constituir uma escola, pois não há uma concordância entre seus teóricos, posto que em sua concepção não havia um grupo de estudo que compartilhasse das mesmas ideias e conviç̧ões.

A doutrina da escola realista americana do Direito, contudo, pode ser resumida no conjunto de normas seguidas pela sociedade, a qual, para ela, é composta pelos juízes e não se referem ao comportamento dos cidadãos (JORGE, 2012). Por conseguinte, interessa aos realistas o Direito efetivamente aplicado, isto é, o produto dos tribunais, e não o Direito posto nos livros - o denominado Direito legislado (NOJIRI, 2005).

Para os realistas, o Direito que deve ser estudado consiste na legislação aplicada ao caso concreto, a qual tenha sido interpretada pelos tribunais. Eles acreditam não estarem as normas postas aptas a guiar a vida em sociedade. Elas apenas devem inspirar os juízes na solução dos casos concretos (NADER, 2010).

Consoante a isso, estes autores consideram que a norma não deve ser usada pelo juiz como argumentação, cabendo a ele então criar a sua própria alegação, desenvolvendo uma atividade hermenêutica. Nesta atividade, portanto, os juízes gozam de ampla discricionariedade para formular a sua técnica interpretativa (NOJIRI, 2005).

Em terras americanas tornou-se muito comum, nas universidades, o ensino de técnicas de argumentação e raciocínio, haja vista o seu sistema jurídico baseado em casos já julgados. Diferentemente da Inglaterra, nos Estados Unidos, ao se aplicar o que já fora decidido anteriormente pelos tribunais, inova-se em relação aos ingleses, uma vez que, na aplicação das decisões já consolidadas, os juízes podem interpretar os julgados, não se fazendo, assim, a sua aplicação em caráter obrigatório absoluto, mas com certa discricionariedade. Desenvolve-se uma atividade hermenêutica acerca de precedente em relação à sua aplicação ao caso concreto a ser decidido (AZEVEDO, 2009).

Faz-se importante ressaltar que determinado conteúdo, o qual jamais será discutido pelos tribunais, será interessante para o Direito como ciência social para o estudo universitário. Com isso, pode-se ter uma visão amplificada do Direito, uma vez que não se ficará adstrito ao estudo do produto dos tribunais, algo que poderia ser considerado uma estagnação do pensamento jurídico (AGUILAR, 1999).

A ideia matriz do realismo norte-americano encontra-se fundada na Common Law e não consiste em um conjunto de regras a respeito dos institutos jurídicos, mas de uma tradição de costumes e hábitos consolidados. O berço da Common Law é a Inglaterra, a qual não sofrera grande influência do Direito romano-germânico, mantendo assim sua tradição consuetudinária (STRECK, 2014).

A conquista do Reino da Inglaterra pela Normandia promoveu várias mudanças, uma delas na administração da Justiça. Com a centralização política, ocorre também um processo de centralização da Justiça, o desenvolvimento de novos procedimentos e remédios, bem como uma nova estrutura de Direito substantivo, este aplicado a todos os cidadãos ingleses, a Common Law (BARBOZA, 2014).

A Common Law consiste em um Direito caracteristicamente de origem anglo-saxônica, ou seja, um Direito consuetudinário tipicamente inglês. Faz-se mister ressaltar que mesmo a Common Law tendo por base os costumes consolidados em uma sociedade, este sistema possui um Direito legislado denominado statute law que seria o Direito estatutário ou legislativo (BOBBIO, 2006). 
A fonte do Direito inglês são as decisões dos tribunais, são elas que exercem o papel de criadoras do Direito, limitando ao magistrado a função de reconhecer a autoridade de seus precedentes. Ao contrário da Civil Law, as normas aqui desempenham uma função secundária, de complementação da jurisprudência. Dessa forma, a norma possui sentido somente em relação à Common Law, e não de maneira autônoma, como no outro sistema (BARBOZA, 2014).

O fato de o Direito inglês ser eminentemente judiciário demonstra o seu caráter prático e casuístico, o qual se nota em seus magistrados, cuja função é a aplicação da Justiça e não de fórmulas preestabelecias do Direito. Cada nova situação pressupõe uma nova regra que se liga ao passado com a finalidade de transmitir o procedimento que permitirá ao juiz alcançar a novidade normativa (BARBOZA, 2014).

Ao aplicar uma regra o juiz deve afirmá-la como norma dentro dos limites e circunstâncias do caso concreto. $\mathrm{Na}$ aplicação do precedente ele buscará sua adequação a partir das razões dos casos anteriormente decididos, caso não encontre correspondência com a lide ou constate que ela não fora considerada anteriormente. Cabe a ele completar e reformular o precedente, para que possa dar à demanda uma solução razoável ao litígio (DAVID, 1997).

Afirma Streck ser a Common Law uma criação do Direito processual, pois com a formação dos direitos subjetivos de maneira empírica, foram aparecendo também as questões controversas. À medida que iam surgindo, era criado um remédio para a sua solução (AZEVEDO, 2009). Esse sistema permaneceu sempre em vigor sendo válido o Direito Estatutário enquanto não contrariar o Direito Consuetudinário, portanto pode-se afirmar que a Common Law funciona em certa medida, como um controle das funções do Legislativo, limitando assim o poder do rei (AZEVEDO, 2009).

O primeiro modelo de Justiça experimentado em território norte-americano foi o sistema inglês. Os colonos que desembarcaram no Novo Mundo trouxeram consigo a Common Law, pois como pregava a Calvin's Case, ${ }^{2}$ ela acompanhava os súditos ingleses aonde fossem.

Nem todas as regras da Common Law britânica conseguiram realmente se efetivar na colônia, pois muitas não se adaptavam à realidade americana, o que era inclusive previsto pela própria Common Law, pois de acordo com a Calvin's Case, o Direito deveria ser aplicado em acordo com a realidade local, ou outras que não eram originadas no Judiciário. As leis votadas no Parlamento de Westminster se aplicariam ao território americano somente se recebessem um decreto especial autorizando (DAVID, 2002).

No Direito americano, assim como no inglês, as leis ou statute law não consistem na fonte primária do Direito, mas isso não quer dizer que os juristas desses países não consideram as regras produzidas pelo legislador, mas sim que eles preferem as normas que já passaram pela interpretação dos tribunais (AZEVEDO, 2009).

\section{O REALISMO JURÍDICO ESCANDINAVO}

Outra corrente do realismo jurídico se desenvolveu nos países escandinavos (Noruega, Suécia e Finlândia) - o Realismo Escandinavo. Essa escola reunia alguns pensadores, entre os quais Hägerström, Lundstedt, Olivecrona e Ross - um grupo de pensadores bem distintos entre si (NOJIRI, 2005).

Esta distinção repousa no fato que nem todos os teóricos mencionados são efetivamente realistas do Direito, como é o caso de Alf Ross, pertencente à Escola de Copenhague. Ele somente pode ser chamado de realista pela proximidade de sua teoria com o Realismo Escandinavo, enquanto os membros da Escola de Upsala: Härgerström, Lundstedt, Olivecrona são mais inclinados a uma Psicologia Jurídica do que à Sociologia propriamente dita (ARNAUD; DULCE, 2000).

Esta escola difere da americana em dois aspectos: em primeiro lugar, apresenta um viés mais especulativo em relação aos problemas jurisprudenciais e, em segundo, mostra um caráter menos psicológico, isto é, eles dedicam menos atenção às questões relacionadas ao sentimento, ou motivação emocional dos membros do Judiciário. $O$ ponto de contato entre as duas teorias está na atitude radicalmente empírica de ambas em relação à vida e ao Direito (BODENHEIMER, 1966).

${ }^{2}$ Decisão jurídica inglesa datada de 1608. Estabelecia que toda a criança nascida na Escócia, após a União das Coroas, estaria sob a égide da Common Law. 
Axel Hägerström é considerado fundador da chamada "Escola de Upsala" e também do movimento realista escandinavo. Entendia este autor o Direito Positivo como um sistema de regras emanadas do Estado, as quais asseguravam vantagens aos indivíduos. Faz também uma distinção entre a norma jurídica e a moral. Segundo Hägerström, a norma tem exigibilidade independente da aceitação de seus destinatários, enquanto a moral vincula-se ao processo de internalização de cada indivíduo (LOPES, 2004).

A. Vilhelm Lundsted, considerado um discípulo de Hägeström, defende que a ciência jurídica deve estar embasada na utilidade pública e não na ideologia. Segundo suas ideias, os fatos reais, que ocorrem na sociedade, entram em confronto constantemente com os fatos jurídicos, os que são apreendidos pela lei, tais como: propriedade, obrigação, entre outros. Os juristas, ao entrarem em contato com o fato, o fazem permeados pela ciência jurídica, a qual os distancia da realidade dos fatos.

Lundstedt elaborou uma técnica que denominou "método do bem-estar social", que, segundo ele, era isento de qualquer avaliação ética. Referia-se ao bem-estar social como convenções consideradas úteis ao ser humano, em uma sociedade, em um dado momento. Para este teórico, o socialmente útil é aquilo que é realmente considerado de interesse social (BODENHEIMER, 1966).

Outro representante da Escola de Upsala é o sueco Karl Olivecrona, que afirma ser a norma uma declaração de vontade, implicando sempre uma relação pessoal. Dessa forma, são imperativos independentes, servindo apenas para sugestionar o comportamento das pessoas. Ele acredita ser toda a força obrigatória do Direito uma ilusão, uma vez que não pode haver obrigações jurídicas no sentido objetivo, pois, em sua concepção, o que realmente existe é um sentimento de dever que se vincula à ideia de obrigação (SOLON, 2000).

A primeira fase de seu pensamento é marcada pela pressão psicológica exercida pela coação, a qual foi por ele atribuída como única explicação para o Direito. Nessa segunda fase, Olivecrona refina sua teoria por meio da Filosofia da Linguagem. Nesse momento a norma, para ele, constitui-se em um imperativo independente, o qual consiste em uma vasta configuração de signos linguísticos de função diretiva. Sendo assim, Olivecrona acredita que a força da norma jurídica independe da vontade do emitente, mas sim de preconceito a respeito de determinados procedimentos formais (SOLON, 2000).

Alf Ross acreditava no Positivismo, pois, para ele, não existem princípios morais universalmente válidos, de caráter superior, os quais vinculam as normas. Ele afirmava que não devemos interpretar as proposições de validade inobservável ou força obrigatória, mas sim como proposições que se referem a fatos sociais (NOJIRI, 2005).

Ross entendia que a função simbólica das normas não era nada mais que uma manifestação da linguagem. Para ele, o significado de uma palavra torna-se mais expressivo quando considerada como parte de uma expressão definida (NOJIRI, 2005). Sua preocupação estendeu-se ao problema da validade, partindo do fato de que o Direito fornece normas não para o comportamento individual, mas sim para os tribunais, concluindo, desta maneira, ser a norma contida na lei válida, quando se pode predizer que ela será aplicada no futuro em um caso concreto (BODENHEIMER, 1966).

Os realistas escandinavos acreditavam que a maioria das pessoas obedece à lei por hábito, sendo desnecessária a utilização da força física, mas eles consideram a ameaça de uma sanção um fator psicológico no cumprimento da lei (BODENHEIMER, 1966). Suas teorias apresentam escopo diverso de seus contemporâneos americanos, pois enquanto estes entendem o realismo como o Direito produzido nos tribunais, os escandinavos preocupam-se em reformular conceitos jurídicos embasados no empirismo (ARNAUD; DULCE, 2000).

Estes teóricos assumem uma postura relativista, negando que as regras jurídicas derivem de princípios imutáveis de Justiça. Criticam o Direito natural, mas não aderem totalmente ao positivismo por considerá-lo uma reverência ao poder estatal e um prolongamento das tradições jusnaturalistas (AGUILAR, 1999).

\footnotetext{
${ }^{3}$ Tal escola de pensamento iniciada por Hägerström recebe este nome em decorrência da Universidade de Upsala, a qual localiza-se na Suécia, na cidade de mesmo nome.
} 
O Direito, para estes pensadores, não se baseia na Justiça, pois na concepção realista ela apenas consiste no sentimento daqueles a quem a lei se dirige, ou seja, os juízes, que por hábito e ou ideologia têm a ordem jurídica como satisfatória. Para eles, os julgamentos fundam-se em sentimentos, convicções pessoais, sendo que em qualquer momento pode ser evocada a Justiça, como fundamentação de suas decisões (BODENHEIMER, 1966).

Cabe ressaltar a posição de Alf Ross a respeito da atividade do juiz na perspectiva do Realismo Escandinavo. Para ele, consiste em uma falácia a máxima de que o juiz deve descobrir o sentido da lei, pois segundo seu entendimento, em muitos casos o juiz não terá condições de estabelecer certamente o significado da norma. Dessa forma, fará conjecturas de acordo com as circunstâncias, realizando assim atividade criadora (NOJIRI, 2005).

\section{CONSIDERAÇÕES ACERCA DO POSITIVISMO JURÍDICO}

No curso do século 19 começa a surgir uma reação contrária à fundamentação do Direito baseado na metafísica, a qual propõe assentar as questões jurídicas em elementos externos ao mundo físico, dificultando assim sua análise empírica. Esse movimento pode ser definido como Positivismo, o qual procura ater-se aos dados fornecidos pela experiência, rejeitando qualquer compreensão da natureza acerca de sua essência (BODENHEIMER, 1966).

O Positivismo Jurídico sofre influência do Positivismo Filosófico, na medida em que rejeita as teses metafísicas sobre a natureza do Direito. Para os positivistas, o estudo do Direito baseia-se em fatos demonstráveis, tais como a criação de normas pelo legislador, mas não podemos afirmar que o Positivismo Jurídico comunga de todas as premissas do Positivismo Filosófico (BODENHEIMER, 1966).

Auguste Comte, filósofo e matemático francês, é tido como precursor do Positivismo. Essa inovadora forma de pensar baseia-se numa concepção cientificista, na qual a ciência é considerada o único conhecimento possível, sendo, portanto, o método das Ciências Naturais o único tido como válido (ARANHA; MARTINS, 1993)

As premissas do Positivismo Jurídico começaram a se fortalecer ao mesmo tempo em que teve início a monopolização do poder político pelo Estado. Sendo assim, as proposições positivistas relacionaram-se com ideias racionalistas sobre a criação e a aplicação do Direito. Tudo isso impulsionado pelo surgimento dos Códigos e das Constituições escritas, em muitos países da Europa, sobretudo na França (DIMOULIS, 2018).

Na Inglaterra não há o emprego da expressão Positivismo Jurídico, mas encontramos elementos típicos do juspositivismo nas obras de Austin e Bentham como: separação entre Direito e moral, definindo assim o Direito como decorrência de mandamentos humanos e sua dependência da autoridade soberana em determinada sociedade (DIMOULIS, 2018).

Os adeptos da Escola Histórica, na Alemanha, são considerados os precursores do Positivismo, uma vez que eles rejeitam o jusnaturalismo e as pretensões universalistas do Direito. Direcionavam seus estudos para a produção normativa de seu país, criticavam o monopólio da produção jurídica nas mãos do Estado e acreditavam que os costumes teriam papel determinante na configuração do Direito de cada país (DIMOULIS, 2018).

Não há consenso entre os positivistas jurídicos sobre a sua vinculação ou não com a Filosofia Positivista. Alguns partidários afirmam que o Positivismo Jurídico adota de maneira genérica a Filosofia Positivista, outros sustentam que ele se liga especificamente ao Positivismo de Comte. Há os que acreditam que importantes expoentes do Positivismo Jurídico, como Alf Ross e Herbert Hart, sofreram influências do Positivismo lógico ou analítico (DIMOULIS, 2018).

Os positivistas têm por objeto de estudo o Direito posto, ou seja, aquele que emana de uma autoridade e por isso possui validade. A eles interessa também conhecer os atos que originam as normas. Desse modo, seus estudiosos buscam entender e explicar o fenômeno jurídico, livre de conceitos metafísicos ou idealistas sobre o Direito (DIMOULIS, 2018).

A denominação Positivismo, sabidamente, não designa somente a teoria de Auguste Comte, mas também outras teorias. Prova disso é o Positivismo Jurídico, o qual se espelha na metodologia aplicada por Comte na averiguação dos fenômenos, anunciando que todos os fatos humanos deveriam ser investigados em suas causas sociológicas e não metafísicas (JÚNIOR, 1980). 
Várias são as abordagens acerca do Positivismo Jurídico. Aqui trataremos apenas de algumas. A primeira abordagem que será apresentada baseia-se na forma como os positivistas veem a relação entre Direito e moral.

O Positivismo Jurídico divide-se em exclusivo e inclusivo. O Positivismo exclusivo defende que o critério moral não pode ser utilizado no Direito como sentido de interpretação, tampouco para conferir validade. Para eles a moral em nenhum momento interfere no conceito de Direito, pois a validade jurídica corresponde a fatos sociais e os mandamentos morais nunca adquirem relevância jurídica (DIMOULIS, 2018).

No Positivismo exclusivo o Direito estabelece-se exclusivamente por fatos sociais, sendo sua existência constatada pela observação das condutas humanas que o criam como convenção social. $O$ juiz, ao criar nova norma, seja para preencher lacunas ou para qualquer outro motivo consoante com crenças morais, não configura ação da moral no Direito, mas sim uma decisão humana que cria um fato social ${ }^{4}$ (DIMOULIS, 2018).

Joseph Raz defende que mesmo que a norma jurídica traga em seu conteúdo referência à moral, isso não a torna jurídica. O elemento crucial está no fato de que ela foi criada por uma fonte autorizada, não importando o conteúdo, tampouco as intenções do criador. Assim, o que constitui o Direito válido é determinado somente por teses que verificam a fonte e/ou origem, deixando de lado conteúdos morais ou de outra natureza (DIMOULIS, 2018).

Em Raz, a autoridade é tida como a única fonte do Direito. Ela existe quando os destinatários da regra a obedecem, pois nela confiam ou porque se sentem por ela intimidados. Assim, não agiriam de forma diversa se a autoridade não emitisse o comando. A decisão de respeitar a lei não pode advir do sentimento interno do destinatário em cumprir a norma, devendo ser influenciado pelo mandamento, pois somente desta forma haverá o exercício de autoridade pelo legislador (DIMOULIS, 2018).

A obediência às ordens emanadas pela autoridade ocorrem sem juízo de valor do destinatário. Desse modo, tem-se que as razões dadas pela autoridade vencem as razões do destinatário. Sob essa perspectiva, Raz defende que os destinatários têm sua vida facilitada pelas autoridades, pois eles não precisam sobrepesar os argumentos a favor ou contra acerca de determinada conduta, essa mediação entre a norma e o destinatário é feita pela autoridade (DIMOULIS, 2018).

O Positivismo inclusivo, também conhecido como incorporacionismo ou Positivismo moderado, parte de uma concepção teórica que tenta conciliar a abordagem positivista com posições da corrente moralista. Os partidários dessa tese sustentam que nem sempre a moral é decisiva para definir o Direito, mas, em algumas sociedades pode ser convencionado considerá-la para determinar a validade e interpretar a norma jurídica vigente (DIMOULIS, 2018).

Os estudiosos do Positivismo Inclusivo reconhecem que nos fundamentos de existência e no conteúdo de leis válidas a moralidade política está presente. Assim, leis elaboradas ou promulgadas por parlamentares, tribunais ou práticas costumeiras não estão isentas de influências morais por parte de seus agentes (DIMOULIS, 2018).

Assim, o conteúdo das normas pode não ter sua origem somente em fontes sociais, dependendo de uma moral substancial. Essa visão de incorporação da moral no Direito estaria relacionada aos ordenamentos modernos, em particular no constitucionalismo, em que há um aceno de uma leitura moral do Direito nos casos de princípios como a dignidade da pessoa humana, a liberdade e a igualdade (DIMOULIS, 2018).

Além da classificação inclusivo/exclusivo podemos citar, como uma classificação do Positivismo Jurídico, a distinção entre Positivismo Analítico e Positivismo Sociológico, elaborada por Bodenheimer. Seu ponto de partida consiste em tomar uma determinada ordem jurídica e dela extrair noções, conceitos e distinções fundamentais, os quais podem ser comparados a outras ordens jurídicas, rastreando elementos comuns entre elas. Ele importa-se com a análise dos temos da lei, buscando, assim, correlações lógicas entre as proposições legais (BODENHEIMER, 1966).

${ }^{4}$ Fato social, para Durkheim, é toda maneira de fazer, fixa ou não, suscetível de exercer sobre o indivíduo uma coerção exterior (DURKHEIM, 2007). 
Quando se dispõe a investigar e descrever as variadas forças sociais, as quais influenciam na formação do Direito Positivo, o Positivismo assume a forma sociológica (BODENHEIMER, 1966), que não será investigada aqui.

O Positivismo Analítico engloba uma pluralidade de teses de diferentes autores, entre os quais podemos citar John Austin, Hans Kelsen e Herbert Hart. Austin foi o fundador da Escola Analítica da Ciência do Direito. Adepto do utilitarismo, defendia a tese de que o propósito ou o fim do governo político soberano era proporcionar a maior felicidade humana possível. Para ele, a ciência do Direito, ou a chamada jurisprudência, deveria se ocupar das leis positivas, sem estabelecer juízo de valor, ou seja, considerar se são boas ou más (BODENHEIMER, 1966).

Por outro lado, a ciência da legislação era um simples ramo da ética, a qual teria como função realizar teste para avaliar as leis positivas e os princípios nos quais se assentavam, para então merecer aprovação. Assim, o jurista se ocupará com a lei como ela é, enquanto ao legislador deve interessar a lei como ela poderá ser. Esse interesse do legislador, todavia, não tem relação com uma lei ideal ou justa (BODENHEIMER, 1966).

Para Austin, o Direito Positivo tem caráter imperativo; a lei é concebida como uma ordem do soberano, todavia ele não considerava lei as determinações que não tivessem caráter geral, ou seja, que obrigassem a uma pessoa ou grupo de pessoas a ações ou tolerâncias próprias de uma classe (BODENHEIMER, 1966).

Austin entendia não ser necessário que a lei fosse emanada somente de um órgão legislativo, ela poderia ser proveniente de um órgão oficial, ao qual o soberano houvesse delegado o poder de legislar. Logo, a decisão judicial normativa era para Austin uma lei positiva (BODENHEIMER, 1966).

As normas emanadas do Judiciário deveriam ter sua força legal autorizada pelo Estado; essa concessão poderia ser feita expressamente, de modo ordinário, ou indiretamente, pela anuência posterior. Essas normas preenchem o mais importante requisito do Direito Positivo, na visão de Austin serem ditadas por um órgão político superior em orientação aos órgãos políticos inferiores (BODENHEIMER, 1966).

Embora a teoria de John Austin não tenha sido muito estudada em seu tempo, mais tarde ela influenciou o desenvolvimento da ciência do Direito na Inglaterra, sobretudo com Herbert Hart, que se tornou um propagador de uma forma mais moderna do Positivismo Analítico (BODENHEIMER, 1966).

$\mathrm{O}$ ordenamento jurídico em Hart é formado por regras primárias em que se encontram o que as pessoas, destinatárias das normas, devem fazer ou não fazer. As regras secundárias têm como finalidade a solução de problemas ocorridos com as normas primárias. Elas se subdividem em: regras de alteração, que promovem a adequação da norma à realidade social; regras de adjudicação, que promovem a dinamicidade e a eficácia no ordenamento jurídico e a regra de reconhecimento, que tem por função estabelecer os requisitos pelos quais as normas jurídicas são consideradas válidas. Ela também tem o papel de delimitar o poder do Estado, uma vez que confere poderes a determinadas pessoas para que elaborem e apliquem as normas jurídicas (JORGE, 2012).

Para Hart, para ser válida, a norma não necessita ser rotineiramente obedecida, mas já a regra de reconhecimento tem por condição de validade ser constantemente acatada, pois sua existência como prática social eficaz só se dá quando cumprida e aceita pelos destinatários da norma (JORGE, 2012).

A regra de reconhecimento não tem por função somente determinar as condições que as normas devem preencher para que sejam consideradas válidas, mas também delimita o poder do Estado. Ela traz consigo, então, uma noção de sistema jurídico, na medida em que faz a distinção entre Direito e outros sistemas normativos, como a moral e as convenções sociais (JORGE, 2012).

Hans Kelsen, em sua Teoria Pura do Direito, propõe o distanciamento de todo viés ideológico do Direito, por exemplo, a Justiça. Não há como dizer que a Justiça representava algo subjetivo, ou até mesmo um determinado valor, de uma pessoa ou grupo. Isso então impossibilitaria dar uma resposta cientifica à questão: $O$ que é a Justiça? (BODENHEIMER, 1966).

Em sua Teoria Pura do Direito ele estabelece como objeto de estudo a norma jurídica, afastando do Direito toda a intromissão de outras ciências, tais como a Psicologia, a moral, a Sociologia, etc. Na concepção kelseniana o Direito pode até ser investigado sob uma perspectiva sociológica, mas isso não faz parte da ciência do Direito no sentido verdadeiro dessa expressão (BODENHEIMER, 1966). 
O Direito para este autor consiste em um sistema ordenado de normas coercitivas, as quais prescrevem a prática ou não de determinada conduta, seguida de uma medida de coação por parte do Estado quando descumprida. O conjunto dessas múltiplas normas tem por unidade uma única fonte, que seria a norma fundamental. É a ela atribuída a aquisição ou a perda de validade de uma norma (BODENHEIMER, 1966).

A norma fundamental, que Kelsen denominou Constituição no sentido lógico-transcendental, não se confunde com a constituição positiva, a Constituição escrita materializada em um documento formal, ou uma Constituição não escrita, que se apoie em um costume. Considerando a hierarquia do ordenamento jurídico, a norma fundamental está no topo. Abaixo dela está a Constituição e então, mais abaixo, as leis. Compete à legislação estabelecer o conteúdo das normas gerais ou processuais, bem como criar órgãos para a sua execução, sejam eles tribunais judiciários ou administrativos (BODENHEIMER, 1966).

A concretização dessas normas gerais não está em si mesma, pois apresenta um caráter abstrato; essa responsabilidade é delegada ao Judiciário. É a autoridade judicante que decide o modo de aplicação de uma norma geral ao caso concreto, desenvolvendo assim atividade declaratória e constitutiva do Direito, sendo seu produto chamado por Kelsen de norma individualizada (BODENHEIMER, 1966).

\section{CONECTANDO O POSITIVISMO JURÍDICO AO REALISMO JURÍDICO}

Positivismo Jurídico e Realismo Jurídico parecem ser duas teorias distintas. A primeira tem como fonte de estudo a norma jurídica, a qual deve ser posta por autoridade competente de acordo como o modo estabelecido no ordenamento jurídico, pois só assim será dotada de validade. O foco dos positivistas não é assim o Direito como ele é, ou seja, a norma como ela realmente é aplicada. O Realismo Jurídico, por sua vez, estuda o Direito aplicado, especificamente o produzido nos tribunais. Para eles não basta à norma ser revestida de validade; ela tem de ser também eficaz. Os realistas entendem o Direito como um conjunto de normas efetivamente seguidas em uma determinada sociedade (BOBBIO, 1995).

Independentemente do requisito da validade ou da eficácia, as duas teorias se aproximam quando colocam o Direito como algo proveniente de uma autoridade. No caso do Positivismo Jurídico, para ser válida a norma deve ser posta por órgão dotado de poder estabelecido pelo ordenamento.

Já no Realismo Jurídico a norma deve ser eficaz, em outras palavras, aplicada pelo juiz, que também é uma autoridade competente, autorizado pelo ordenamento jurídico. Dessa forma, ambas as teorias consideram o Direito com base na figura da autoridade.

As duas teorias primam pelo estudo do Direito estatal, rejeitando o dualismo jurídico (Direito Natural e Direito Positivo), e se atêm somente ao monismo jurídico (Direito Positivo) (BOBBIO, 1995).

Tanto o Positivismo Jurídico quanto o Realismo Jurídico rejeitam o Direito Natural, ou seja, um Direito fundado em bases metafísicas, uma vez que o objeto de estudo de ambas assenta-se em fatos demonstráveis, como a norma jurídica e as decisões judiciais.

Outro pondo de contato entre as duas teorias pode ser encontrado no Positivismo exclusivo, que sustenta não poder ser a moral utilizada para constatar a validade das normas jurídicas e nem para interpretá-las. A atuação do magistrado, na visão desses teóricos, consiste na criação de um fato social.

Ao decidir sobre determinado caso, o magistrado cria uma nova norma, seja para preencher uma lacuna ou por qualquer outro motivo. Ele o faz, muitas vezes, de acordo com crenças morais, porém essa moral não influencia o Direito, mas a decisão humana que cria o fato social (DIMOULIS, 2018).

Nesse segmento, Alf Ross, representante do realismo escandinavo, defende não haver uma mora universal à qual seja possível vincular a norma jurídica. Ao fazer essa afirmação Ross se coloca como positivista exclusivo, uma vez que refuta a possibilidade de juízos morais prevalecerem de forma superior à norma jurídica.

Ao discorrer sobre a moral, Alf Ross nos lembra que, em relação ao comportamento moral, não há como se estabelecer um juízo individualizado. Assim, a atuação do legislador ou julgador é inexistente, cada um arbitra e decide o que julga certo ou errado, em consonância com suas convicções pessoais. Sendo assim, não há que se falar em uma moral abrangente a todos, mas sim padrões os quais podemos caracterizar como predominantes ou típicos (NOJIRI, 2005). 
Outro elemento importante do Positivismo Jurídico é a coação, pois é por meio dela que a norma jurídica é obedecida. Ao Estado cabe a função de exercer a coação a quem deixar de cumprir a regra posta, fazendo assim com que o Direito se efetive. Com isso, o poder estatal por vezes utiliza-se da força, autorizada pelo ordenamento para coibir qualquer violação do Direito.

Os realistas não renegam a coação como fator de concretização do Direito posto. Ross a considera fator importante para o cumprimento da regra posta, e evidencia as consequências de sua aplicação:

[...] Devemos insistir no fato de que a relação entre as normas jurídicas e a força coexiste em que tais normas dizem respeito à aplicação da força e não são protegidas por meio da força. [...] [...] Um sistema jurídico nacional é um sistema de normas que se referem ao exercício da força física [...] (ROSS apud BOBBIO, 1995).

Outro ponto de conexão entre o Positivismo Jurídico e o Realismo Jurídico encontra-se na teoria de Herbert Hart. Teórico ligado à corrente do Positivismo Analítico, Hart propõe duas classes de regras, as quais ele denominou de primárias e secundárias. As primeiras seriam as normas destinadas a regulamentar o comportamento das pessoas, definindo o que seria permitido ou proibido dentro de uma sociedade.

As regras secundárias seriam responsáveis por dirimir possíveis problemas relacionados com as regras primárias. Não sendo essa sua única função, elas também são responsáveis por promover a adequação da norma à realidade social. Nota-se aqui, nesta função, que tal diretriz executa a atribuição que no realismo é ocupada pelo magistrado.

Os realistas acreditam que o juiz, ao aplicar a norma ao caso concreto, realiza um ajustamento do texto normativo, sem de fato alterá-lo. Dessa forma, a aproximação das duas teorias se dá por compartilharem da preocupação com a adequabilidade da norma e consequentemente sua atualização, pois, para os realistas, o juiz, ao aplicar a norma, corrige as possíveis distorções entre a lei e o fato por ela regulado.

Ainda na teoria hartiana encontramos a regra de adjudicação, a qual é responsável por promover a dinamicidade e eficácia ao ordenamento jurídico. Nesse tópico da teoria, clara é a preocupação com a efetividade da norma. Assim como os realistas, Hart leva em consideração a eficácia da norma e não somente sua validade, como alguns positivistas.

Por fim a regra de reconhecimento, cuja atribuição, além de delimitar o poder do Estado, consiste em delegar poderes às pessoas que elaboram e aplicam as normas, e é responsável pela autorização da produção de normas (Legislativo) e sua aplicação (Judiciário), ou seja, ela determina quem será a autoridade que desempenhará esses papéis.

A proximidade temporal entre o Positivismo Jurídico e o Realismo Jurídico, pois ambas as correntes ocorrem no século 19, faz com que elas compartilhem alguns de seus princípios. Esse intercâmbio teórico por vezes impede que se estabeleça uma distinção clara entre Positivismo e Realismo Jurídicos.

\section{CONCLUSÃO}

O Realismo Jurídico tem como uma de suas premissas a rejeição ao formalismo jurídico, para seus teóricos o mais fator mais importante está na eficácia da norma, ou seja, sua produção de resultados, enquanto o Positivismo Jurídico tem por escopo a validade da norma, a qual deve ser posta por autoridade competente.

Apesar de elegerem propósitos distintos de investigação, as duas teorias em determinados pontos colidem suas posições. Ao tratarem da autoridade o Positivismo e o Realismo colocam-na como proveniente do Estado. Para os positivistas, a norma deve ser posta por autoridade competente; já para os realistas, o Direito deve provir dos tribunais. Note-se que ambas as autoridades têm um único fundamento para o serem, o autorizamento estatal.

Tanto o legislador quanto o magistrado necessitam de uma regra estatal para exercerem o arbítrio da força. Deste modo restou demonstrado que ambas as teorias possuem pontos de conexão entre si. Positivismo e Realismo partilham de ideias comuns relativas aos conceitos de Direito e sua aplicabilidade. 


\section{REFERÊNCIAS}

AGUILAR, Fernando Herren. Metodologia da ciência do direito. 2. ed. São Paulo: Max Limonad. 1999.

ARANHA, Maria Lúcia de Arruda; MARTINS, Maria Helena Pires. Filosofando: introdução à filosofia. 2. ed. rev. e atual. São Paulo: Moderna. 1993.

ARNAUD, André-Jean; DULCE, Maria José Fariñas. Introdução à Análise Sociológica dos Sistemas Jurídicos. Rio de Janeiro: Renovar, 2000.

AZEVEDO, Marcelo Antônio Duarte. Súmula vinculante: o precedente como fonte do Direito. São Paulo: Centro de Estudos da Procuradoria Geral do Estado de São Paulo, 2009.

BARBOZA, Estefânia Maria de Queiroz. Precedentes judiciais e segurança jurídica: fundamentos e possibilidades para a jurisdição constitucional brasileira. São Paulo, SP: Saraiva, 2014. p. 44.

BOBBIO, Norberto. O positivismo jurídico: lições de filosofia do direito. São Paulo: Ícone, 1995.

BODENHEIMER, Edgar. Ciência do Direito: filosofia e metodologia jurídicas. Rio de Janeiro: Forense, 1966.

DAVID, René. O direito inglês. São Paulo: Martins Fontes, 1997.

DAVID, René. Os grandes sistemas do direito contemporâneo. 4. ed. São Paulo: Martins Fontes, 2002.

DIMOULIS, Dimitri. Positivismo jurídico: teoria da validade e da interpretação do direito. 2. ed. Porto Alegre: Livraria do Advogado. 2018.

DURKHEIM, Émile. Fato social e divisão do trabalho. São Paulo: Ática, 2007.

JORGE, Cláudia Chaves Martins. Realismo jurídico e Hart: um debate sobre a indeterminação do Direito. Rio de Janeiro: Lumen Juris. 2012.

JÚNIOR, Tércio Sampaio. A ciência do direito. 2. ed. São Paulo: Atlas. 1980.

LOPES, Mônica Setti. Realismo jurídico: o discurso jurídico e a apreensão da realidade pontual. Revista da Faculdade de Direito da Universidade Federal de Minas Gerais, Belo Horizonte: Universidade Federal de Minas Gerais, n 45, p 297-340, 2004. Disponível em http://www.direito.ufmg.br/revista/index.php/revista/article/view/1298/1230. Acesso em: 8 nov. 2015.

NADER, Paulo. Filosofia do direito. 18. ed. Rio de Janeiro: Forence, 2010.

NOJIRI, Sérgio. A interpretação judicial do direito. São Paulo: Revista dos Tribunais, 2005.

SOLON, Ari Marcelo. Dever jurídico e teoria realista do direito. Porto Alegre: Sergio Antonio Fabris, 2000.

STRECK, Lenio Luiz; ABBOUD, Georges. O que é isso - o precedente judicial e as súmulas vinculantes? 2. ed. Porto Alegre: Livraria do Advogado, 2014. 